\title{
Correction: Minimal residual disease quantification by flow cytometry provides reliable risk stratification in T-cell acute lymphoblastic leukemia
}

\section{S. Modvig • H. O. Madsen - S. M. Siitonen · S. Rosthøj - A. Tierens • V. Juvonen - L. T. N. Osnes $\cdot$ H. Vålerhaugen M. Hultdin - I. Thörn - R. Matuzeviciene $\cdot$ M. Stoskus - M. Marincevic $\cdot$ L. Fogelstrand - A. Lilleorg $\cdot$ N. Toft · O. G. Jónsson - K. Pruunsild · G. Vaitkeviciene · K. Vettenranta - B. Lund · J. Abrahamsson · K. Schmiegelow • H. V. Marquart}

Published online: 10 December 2019

(c) Springer Nature Limited 2019

\section{Correction to: Leukemia}

https://doi.org/10.1038/s41375-018-0307-6

Since the publication of the original paper, the authors realized in the analyses of day 15 MRD $<25 \%$ and day 29 MRD data and outcome, three patients were misclassified due to non-censoring of event after HSCT. All three were stratified concordantly by FCM and PCR, two above (one relapse and one non-relapse related death) and one (relapse) below the cutoff level of $10^{-3}$. There is no change in the conclusions of the paper. An additional seven were misclassified but had day 15 MRD levels $>0.25$ and thus did not affect further analyses.

The original article can be found online at https://doi.org/10.1038/ s41375-018-0307-6. 
A
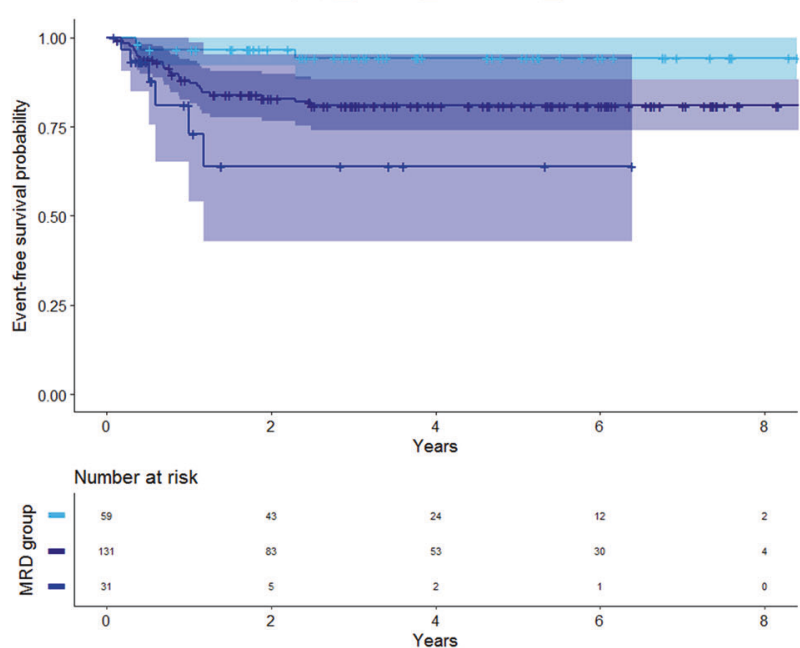

C
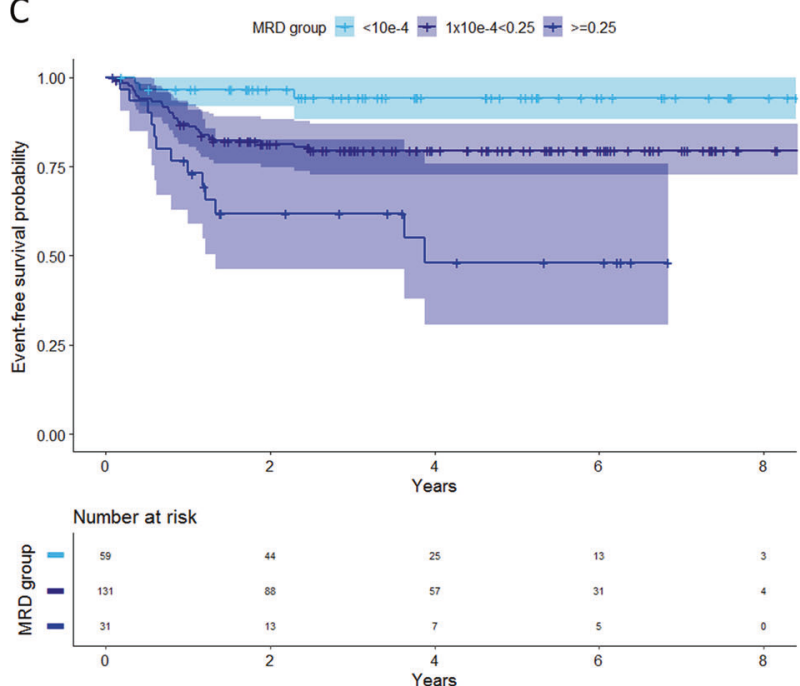

B
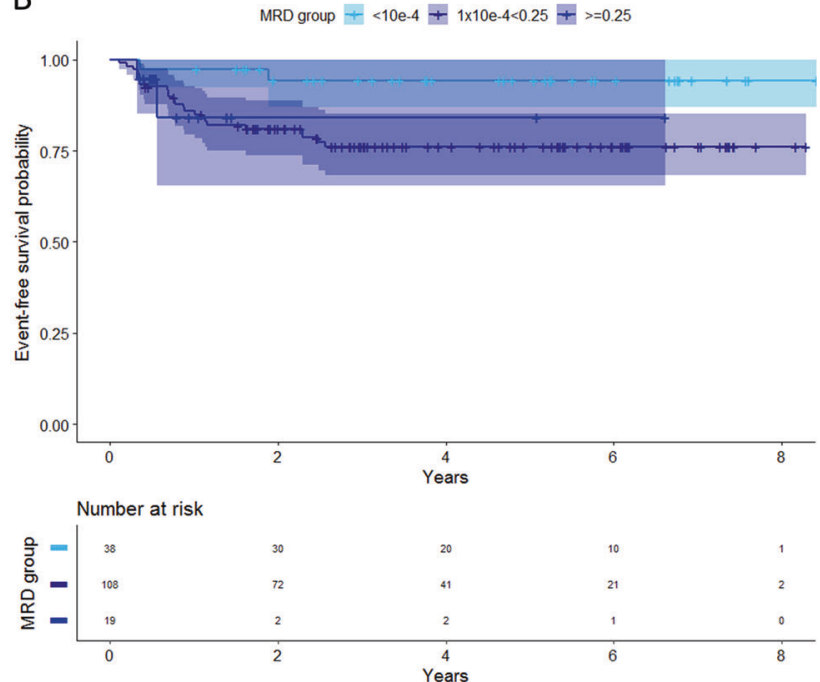

D
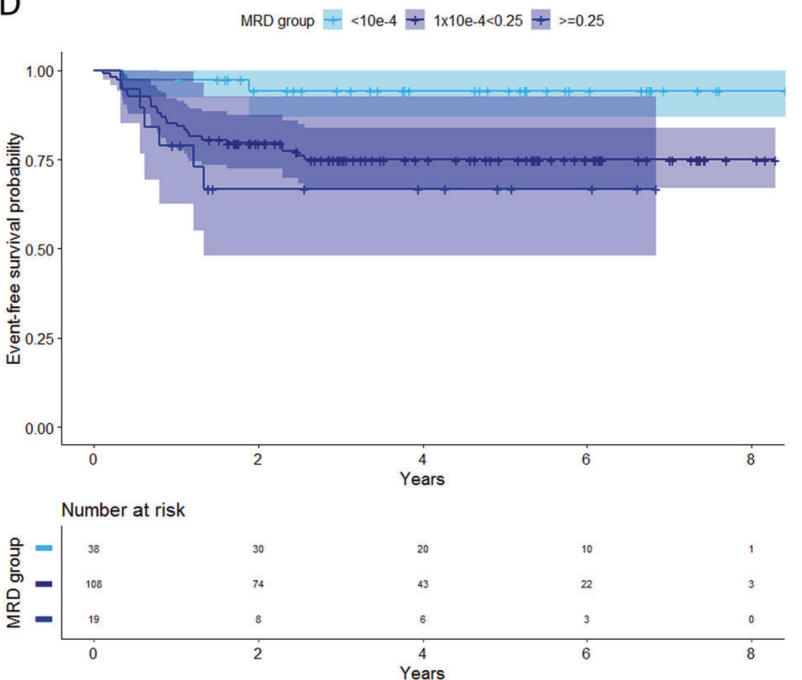

Fig. 1 Day 15 FCM-MRD (a) and PCR-MRD (b) levels and EFS with censoring at time of HSCT. Day 15 FCM-MRD (c) and PCR-MRD (d) levels and EFS with no censoring at time of HSCT.

Table 1 Day 29 FCM and PCR-MRD values and EFS and CIR before and after correction for the three cases.

\begin{tabular}{lcccc}
\hline MRD level & EFS before correction & EFS after correction & CIR before correction & CIR after correction \\
\hline PCR-MRD & & & & $5.3(0.2-10.4)$ \\
$<10^{-4} /$ undetectable & $90.8(83-98)$ & $92.1(86.2-98.4)$ & $6.6(1-12)$ & 0 \\
$10^{-4}$ to $<10^{-3}$ & $91.4(82.6-100)$ & $91.4(82.6-100)$ & 0 & $24.6(9.5-39.7)$ \\
$10^{-3}$ to $<10^{-2}$ & $62.74(48.2-81.7)$ & $62.74(48.2-81.7)$ & $24.6(9.5-39.7)$ & $5.7(0.8-10.5)$ \\
FCM-MRD & & & & $6.6(1.5-12)$ \\
$<10^{-4} /$ undetectable & $86.0(79-94)$ & $87.0(80.0-94.9)$ & $9.5(0.6-18.4)$ & $20.5(0.6-18.4)$ \\
$10^{-4}$ to $<10^{-3}$ & $83.6(73.2-95.5)$ & $83.6(73.2-95.5)$ & $20.1(5.7-35)$ & $20.6(5.8-35.4)$ \\
$10^{-3}$ to $<10^{-2}$ & $70.2(56-89)$ & $72.8(58.3-90.9)$ & & \\
\hline
\end{tabular}

No change in $p$-value significance for the reported comparisons in the paper 